\title{
Biogenic gold nanotriangles from Saccharomonospora sp., an endophytic actinomycetes of Azadirachta indica A. Juss.
}

\author{
Vijay C Verma ${ }^{1,3^{*}}$, Swechha Anand ${ }^{1}$, Christian Ulrichs ${ }^{2}$ and Santosh K Singh ${ }^{1}$
}

\begin{abstract}
Microbial biofabrication is emerging as eco-friendly, simpler, and reproducible alternative to chemical synthesis of metals and semiconductor nanoparticles, allowing generation of rare geometrical forms such as nanotriangles and nanoprisms. Highly confined nanostructures like triangles/prisms are interesting class of nanoparticles due to their unique optical properties exploitable in biomedical diagnostics and biosensors. Here, we report for the first time a single-step biological protocol for the synthesis of gold nanotriangles using extract of endophytic actinomycetes Saccharomonospora sp., isolated from surface sterilized root tissues of Azadirachta indica A. Juss., when incubated with an aqueous solution of chloroaurate ions $\left(\mathrm{AuCl}_{4}^{-} / 1 \mathrm{mM}\right)$. Thin, flat occasionally prismatic gold nanotriangles were produced when aqueous chloroaurate ions reacted with the cell-free extract as well as with the biomass of endophytic Saccharomonospora. It was evidenced from sodium dodecyl sulfate-polyacrylamide gel electrophoresis analysis that proteins of 42 and $50 \mathrm{kD}$ were involved in biosynthesis as well as in stabilization of the nanoparticles. The particle growth process was monitored by UV-vis spectroscopy, and the morphological characterization was carried out by transmission electron microscopy and atomic force microscopy together with X-ray powder diffractions. Although the exact mechanism for this shape-oriented synthesis is not clear so far, the possibility of achieving nanoparticle shape control in a microbial system is exciting.
\end{abstract}

Keywords: Azadirachta indica, Endophytic microbes, Gold nanotriangles, Biofabrication, Saccharomonospora sp

\section{Background}

Metal nanoparticles (NPs) are of great interest due to their specific function, determined by their size, shape, composition, and crystallinity [1]; therefore, nowadays controlled synthesis of metal nanoparticles with welldefined shape and size is among one of the most fascinating aspects of nanoparticle research. The combination of size and shape provides very unique electronic, magnetic, catalytic, and optical properties to these metal nanoparticles that can be exploitable in the rapidly growing nanoindustries. There are exciting potential of nanoparticles in catalysis [2-7], DNA sequence recognition [8-10], nonlinear optical devices [11], biological sensors [12,13], information storage [14], and plasmonics

\footnotetext{
* Correspondence: chandravcv@gmail.com

${ }^{1}$ Centre of Experimental Medicine and Surgery, Institute of Medical Sciences, Banaras Hindu University, Varanasi 221005, India

${ }^{3}$ Department of Microbiology, Institute of Medical Sciences, Banaras Hindu University, Varanasi 221005, India

Full list of author information is available at the end of the article
}

[15]. These properties are mainly due to their optical and electronic attributes modulated by their shape and size $[16,17]$. The engineered NPs might be utilized in interesting applications related to biomedical science and other areas like optics and electronics $[4,12,18-20]$. Currently, many chemical synthesis methods are employed and modified accordingly to control the physical and optical properties of metal NPs. Many of these protocols are still in the phase of modification and development to be able to control over the crystal growth and aggregation of NPs [21-22]. A novel approach for the synthesis of highly structured nanomaterials is the microbe-mediated synthesis, although microbial application for remediation of toxic metals were reported since long back, but their use to synthesize advanced materials at nanoscale has been recently become more common [23-28]. Several bacterial and fungal strains such as bacteria Lactobacillus [29], fungi Verticillium and Fusarium spp. [30,31], and actinomycetes Thermomonospora and 
Rhodococcus spp. [32-34] have the potential to bio-reduce the metal ions especially gold into several well-defined shape and sizes. Gold and silver nanoparticles of triangular morphology are particularly interesting for investigation because of their potential biomedical applications $[35,36]$. The synthesis of nanoparticles using chemical methods (Turkevich recipe) has been reported and used routinely, but often these chemically synthesized gold nanotriangles are less stable, in addition to the toxic byproducts of these reactions that create environmental hazards and potential risk to the human lives in several means [37]. Thus, microbe-mediated synthesis of nanomaterials of desired shape should be a good alternative to the chemical method that can effectively reduce environmental toxicity. Earlier, our group has made successful efforts in the biosynthesis of silver and gold nanoparticles from endophytic microbes [38-39]; besides that, a few other endophytic strains were also reported for their potential in biosynthesizing the nanomaterials [35]. Here in this report, we propose the single step 'green-synthesis' of gold nanotriangles from an endophytic actinomycetes Saccharomonospora sp. isolated from sterilized root tissues of Azadirachta indica A. Juss. plant. This is the first report about the potential of this strain Saccharomonospora sp. in synthesis of gold nanoparticles. In particular, we studied the reduction of aqueous chloroaurate ions by both the biomass as well as the fermentation extract of the Saccharomonospora sp. Under given conditions we observed a rapid extra-cellular growth of gold nanoparticles especially triangles that are stable in the solution.

\section{Methods}

\section{Materials and instruments}

Hydrogen tetrachloroaurate $\left(\mathrm{HAuCl}_{4} \cdot 3 \mathrm{H}_{2} \mathrm{O}\right)$ was purchased from Aldrich chemicals (St. Louis, MO, USA). Ultrapure deionized water (Milli Q; Millipore Corporation, Billerica, MA, USA) was used throughout the experiments. Transmission electron microscopy was performed using TECNAI 12v.G ${ }^{2}$ instruments (FEI Corp., Hillsboro, OR, USA) operating at $120 \mathrm{kV}$, and micrographs were taken after drop coating with $100 \mu \mathrm{l}$ of nanoparticles on a carbon-coated copper transmission electron microscope (TEM) grid of 300 mesh size. UV-visible spectra were obtained with a Hitachi UV-2910 detector (Hitachi America Ltd., Brisbane, CA, USA).

\section{Isolation of endophytic Saccharomonospora sp.}

Isolation of Saccharomonospora sp. was carried out from surface-sterilized root tissues of $A$. indica A. Juss. sampled from several of its natural habitats in northern India including the campus of Banaras Hindu University, as previously described [40]. Briefly, the root tissues were cut in to small segments $(5 \mathrm{~cm})$ and rinsed in running tap water for 10 min followed by a rinse in sterile distilled water. After successive surface treatment in $70 \%$ ethanol (for $5 \mathrm{~min}$ ), followed by 2 min dip into 5\% sodium hypochlorite solution and then again rinsed in 90\% ethanol for $1 \mathrm{~min}$, the surface-treated root tissues were then kept in $10 \%$ $\mathrm{NaHCO}_{3}$ to reduce growth opportunity for any fungal strains. Then the tissues were again rinsed three times in sterilized distilled water and aseptically cut into small pads $\left(0.5 \times 0.5 \mathrm{~cm}^{2}\right)$. The small pads were carefully placed onto potato dextrose agar plates (supplemented with $50 \mu \mathrm{g} / \mathrm{ml}$ cyclohexamide to control fungal growth and $20 \mu \mathrm{g} / \mathrm{ml}$ of tetracycline to restrict bacterial growth) and incubated at $25^{\circ} \mathrm{C}$ for 20 days until the growth of endophytic actinomycetes appeared. Based on literature and other morphotaxonomic features [40] as per the Bergey's manual, one of the actinomycetes was identified as Saccharomonospora sp.

\section{SDS-PAGE and protein profiling of Saccharomonospora sp.}

To gain further insight into the role of specific proteins responsible for the generation of the triangular gold nanoparticles (AuNPs), we carried out the protein profiling of endophytic Saccharomonospora sp. by sodium dodecyl sulfate-polyacrylamide gel electrophoresis (SDS-PAGE) analysis. The total proteins from Saccharomonospora (Sc) extract and Sc-AuNPs reaction supernatants were resolved on $4 \%$ to $20 \%$ tris-glycine minigel followed by coomassie brilliant blue staining. The harvested biomass of the endophytic Saccharomonospora sp. was used to prepare an extract for the protein estimation. The nanoparticles contained in the protein extracts were centrifuged at $20,000 \times g$. After centrifugation, $2 \mathrm{ml}$ of the supernatant was concentrated to $300 \mu \mathrm{l}$ by using membrane filters. In separate microcentrifuge tubes, $50 \mathrm{ml}$ of each Saccharomonospora extract and gold nanoparticle reaction supernatant was mixed with equal volumes of $\times 2$ Laemmli sample loading buffer with 2-mercaptoethanol and were heated at $95^{\circ} \mathrm{C}$ for $5 \mathrm{~min}$, and $20 \mu \mathrm{l}$ of each of the samples was resolved on a tris-glycine ( $4 \%$ to $20 \%$ ) minigel. One well of the gel was loaded with $10 \mu \mathrm{l}$ of standard protein molecular weight marker and the gel was subsequently stained with coomassie brilliant blue stain.

\section{Biofabrication of gold nanotriangles}

Actinomycetes biomass used for biosynthetic experiments was grown aerobically in liquid medium containing the following per liter: $10 \mathrm{~g}$ dextrose, $4.0 \mathrm{~g}$ casein hydrolysate, $0.5 \mathrm{~g} \mathrm{~K}_{2} \mathrm{HPO}_{4}, 0.2 \mathrm{~g} \mathrm{MgSO}_{4} \cdot 7 \mathrm{H}_{2} \mathrm{O}, 0.1 \mathrm{~g} \mathrm{CaCl}_{2} \cdot 2 \mathrm{H}_{2} \mathrm{O}$, $10 \mathrm{mg}$ ferric citrate, $0.01 \mathrm{mg} \mathrm{CoSO}_{4} \cdot 7 \mathrm{H}_{2} \mathrm{O}, 0.1 \mathrm{mg}$ $\mathrm{CuSO}_{4} \cdot 5 \mathrm{H}_{2} \mathrm{O}, 1.5 \mathrm{mg} \mathrm{H}_{3} \mathrm{BO}_{3}, 0.8 \mathrm{mg} \mathrm{MnSO}_{4} \cdot \mathrm{H}_{2} \mathrm{O}$, $0.2 \mathrm{mg}\left(\mathrm{NH}_{4}\right)_{6} \mathrm{Mo}_{7} \cdot \mathrm{O}_{24} \cdot 4 \mathrm{H}_{2} \mathrm{O}$, and $0.6 \mathrm{mg} \mathrm{ZnSO}_{4} \cdot 7 \mathrm{H}_{2} \mathrm{O}$ in $1,000 \mathrm{ml}$ of deionized water. The Erlenmeyer flasks were inoculated with spores and incubated at $26^{\circ} \mathrm{C} \pm 2^{\circ} \mathrm{C}$ with shaking (150 rpm) for $72 \mathrm{~h}$ up to 25 days. After the incubation the biomass was filtered (Whatman filter paper 
no. 1; Whatman International Ltd., Banbury, Oxon, Oxford, UK) and then extensively washed with distilled water to remove any medium component adhered with the biomass. Fresh and clean biomass was taken into the Erlenmeyer flasks containing $100 \mathrm{ml}$ of Milli Q deionized water. The flasks were agitated at the same conditions as described above for $5 \mathrm{~min}$, and then the biomass was filtered again and was used in next experiments. About $20 \mathrm{~g}$ (wet weight) of biomass was brought into contact with $100 \mathrm{ml}$ aqueous $1 \mathrm{mM} \mathrm{HAuCl}_{4}$ solution in an Erlenmeyer flask and incubated on an orbital shaker at $200 \mathrm{rpm}$ at room temperature. The crude fermentation extract is also used as spent free reducing agent when challenged with $\mathrm{HAuCl}_{4}(1 \mathrm{mM}$ of final concentration). An aliquot of $10 \mathrm{ml}$ fermentation extract was added into $90 \mathrm{ml}$ of $1 \mathrm{mM} \mathrm{HAuCl}_{4}$ and incubated as mentioned above. Aliquots of the reaction mixture solution were removed periodically for UV-vis spectroscopic measurements which were operated at a resolution of $1 \mathrm{~nm}$.

\section{Characterization of gold nanotriangles}

Observation of the color change in the cell filtrate after treatment with $\mathrm{HAuCl}_{4}$ was the preliminary detection of the formation of gold nanoparticles. Gold nanoparticles were isolated and concentrated by repeated (4-5 times) centrifugation of the reaction mixture at $15,000 \mathrm{~g}$ for $20 \mathrm{~min}$. The characterization of gold nanotriangles was carried out by X-ray powder diffractions (XRD) ( $\mathrm{Cu}-\mathrm{K} \alpha$ radiation source) using a $12 \mathrm{~kW}$ rotating $\mathrm{Cu}$ anode based Rigaku (Tokyo, Japan) powder diffractometer (RINT 2000/ PC series) operating in Bragg-Brentano geometry and fitted with a curved crystal graphite monochromator in the diffraction beam and a high temperature attachment. Finally,

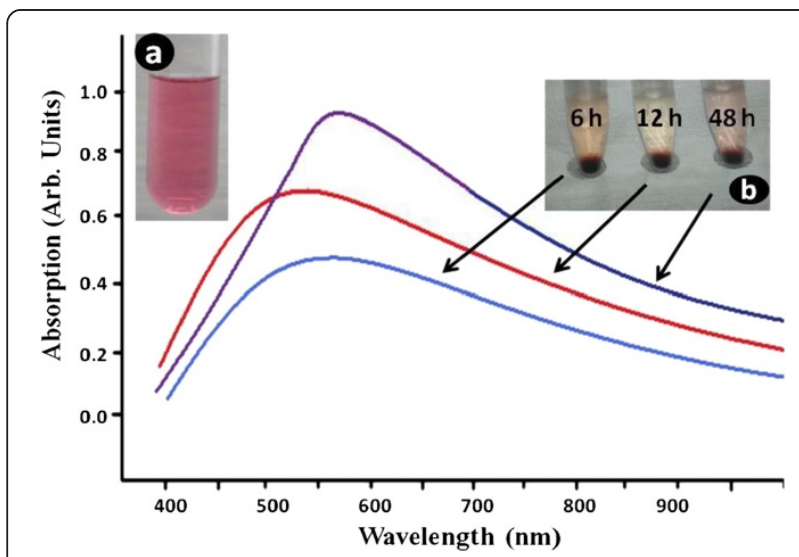

Figure 1 UV-vis spectra. UV-vis spectra as a function of reaction time of an aqueous solution of $1 \mathrm{mM} \mathrm{HAuCl}_{4}$ with the filtrate of Saccharomonospora sp. biomass. Inset (a) shows initial change in the color of reaction mixture. Inset (b) shows the picture of the tubes containing the filtrate of the Saccharomonospora biomass in an aqueous solution of $1 \mathrm{mM} \mathrm{HAuCl}_{4}$ at the beginning of the reaction $6 \mathrm{~h}$ (ca. 536) and after 12 and $48 \mathrm{~h}$ (ca. 560) of the reaction.

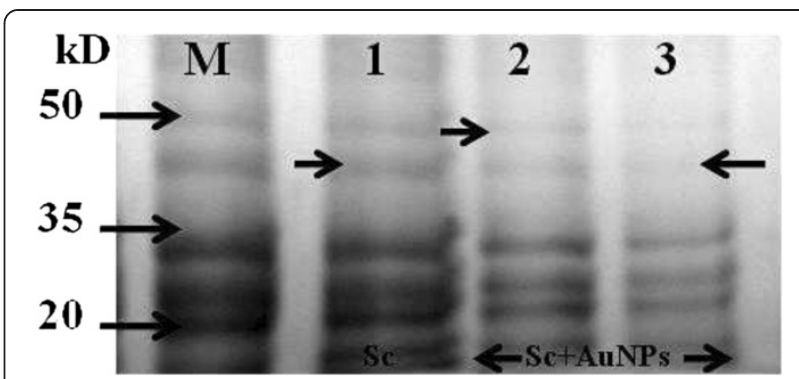

Figure 2 SDS-PAGE profile of proteins extracted from endophytic Saccharomonospora sp. Lane M: standard molecular weight marker; lane 1: Saccharomonospora (Sc) protein extract; lanes 2 and 3: Sc-AuNPs reaction supernatant. Proteins of about 42 and 50 $\mathrm{kD}$ which appeared in the crude extract (lane 1) gradually

disappears when challenged with the aqueous chloroaurate ions (lanes 2 and 3); this indicates that the proteins of this size are involved in the biosynthesis and/or stabilization of gold nanoparticles.

the gold nanoparticles were characterized by measurements of their vertices under transmission electron microscopy (Tecnai (FEI)-12v.G ${ }^{2}$ ) and surface topology was measured by atomic force microscopy (AFM) in the contact mode on a VEECO Digital Instruments (Plainview, NY,

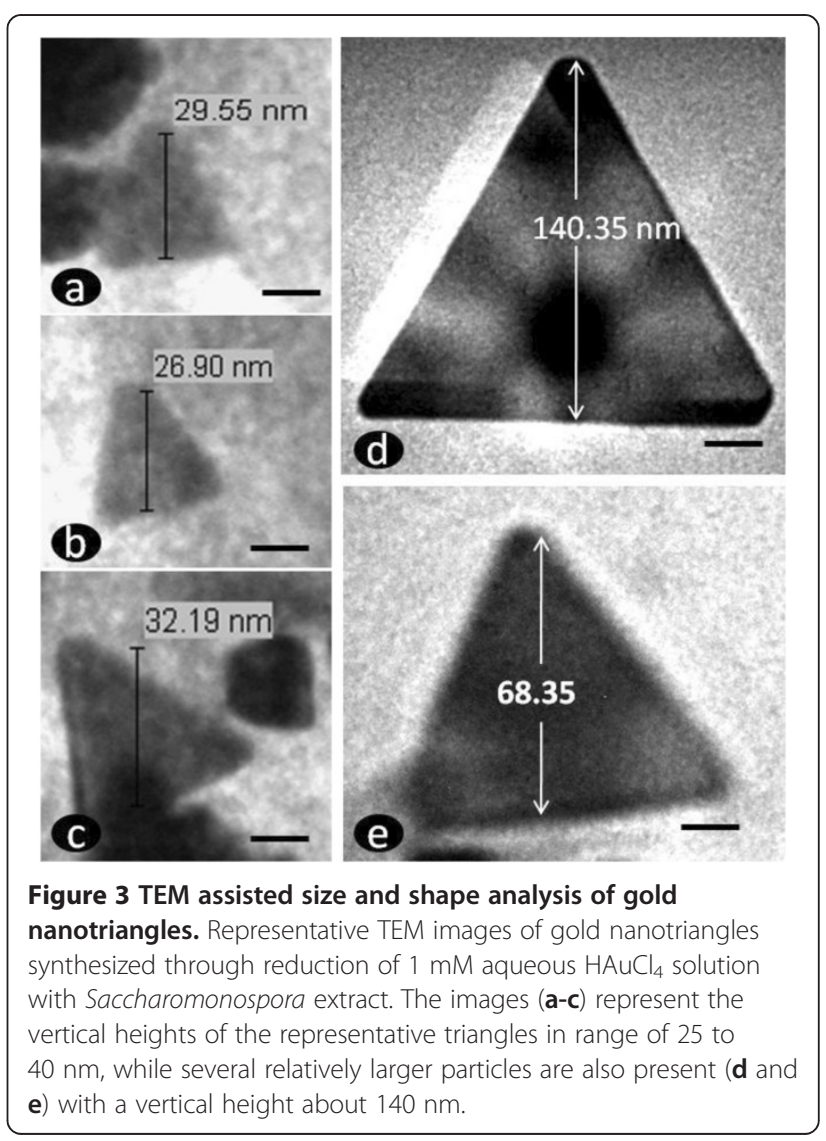




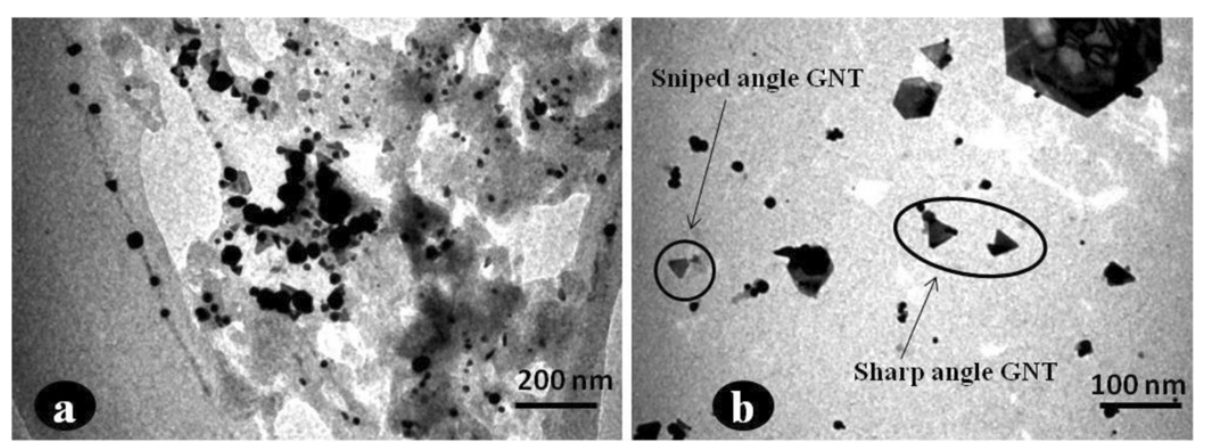

Figure 4 Thin section of the treated biomass showing the presence of the gold nanotriangles. The thin section of the treated biomass shows the presence of the gold nanotriangles (GNTs) on the inner wall of the cells/tissues. Mostly, the triangular nanoparticles are visible but many other shapes are also formed (a). Triangles also represent several morphologies like sharp to snipped angle (b).

USA) multimode scanning probe microscope equipped with a Nanoscope IV controller.

\section{Results}

When the biomass and fermentation extracts of Saccharomonospora sp. were brought into contact with $\mathrm{HAuCl}_{4}$ aqueous solution, a rapid change in the color of the reaction mixture was observed after $6 \mathrm{~h}$ which further deepened after $12 \mathrm{~h}$ of incubation, and the initial transparent color of the reaction mixture turns into pink color (Figure 1, inset a). After $48 \mathrm{~h}$ of incubation, this completely turns into a dark tan color (Figure 1 , inset b) which indicates the extracellular biosynthesis. Within $6 \mathrm{~h}$ of reaction incubation, the surface plasmon resonance (SPR) peak was observed at ca.536, which further intensifies after $12 \mathrm{~h}$, but the shift of the SPR peak at $48 \mathrm{~h}$ of incubation from 536 to $560 \mathrm{~nm}$ indicates a sharp reduction in the particle size. The SDS protein profiling as shown in Figure 2, lane $M$ corresponds to the standard protein marker, lane 1 corresponds to the total proteins from Saccharomonospora extract, and lanes 2 and 3 represent Sc-AuNPs reaction supernatant. Comparisons of lanes 2 and 3 , with those of lane 1 revealed that the bands corresponding to 42 and $50 \mathrm{kD}$ in lane 1 gradually decline in lane 2 and almost disappears in lane 3. The Figure 3 represents the TEM micrograph of the gold nanoparticles. Apparently, flat gold nanoparticles of triangular shape were frequently observed in the TEM images. The triangles representing the vertical heights of $26.90 \mathrm{~nm}$ (Figure 3a), $29.55 \mathrm{~nm}$ (Figure 3b), and $32.19 \mathrm{~nm}$ (Figure 3c) were among a few very small nanotriangles that recovered; but besides these, some large triangles with a vertical height of $140.35 \mathrm{~nm}$ (Figure 3d) and $68.35 \mathrm{~nm}$ (Figure 3e) were also recovered. Aside from gold nanotriangles, there were large number of other shapes like hexagons and rough spheres also observed (Figure $4 \mathrm{a}$ ). The average particles size was 40 to $60 \mathrm{~nm}(43 \%)$ as per vertical heights are concerned (Figure 5a); many others range in between 60 and $80 \mathrm{~nm}$ heights. Thus, a typical triangle as per our measurement was likely to have vertical height of 40 to $60 \mathrm{~nm}$, while the edge vertices were in between 60 and $80 \mathrm{~nm}$ (Figure 4b). A typical X-ray diffractogram of gold nanoparticles was shown in Figure 6. It was observed that the diffraction spot indicates the triangular nature of the gold nanoparticles, since they are highly [111]-oriented with the top surface normal to the electron beam. Thus,

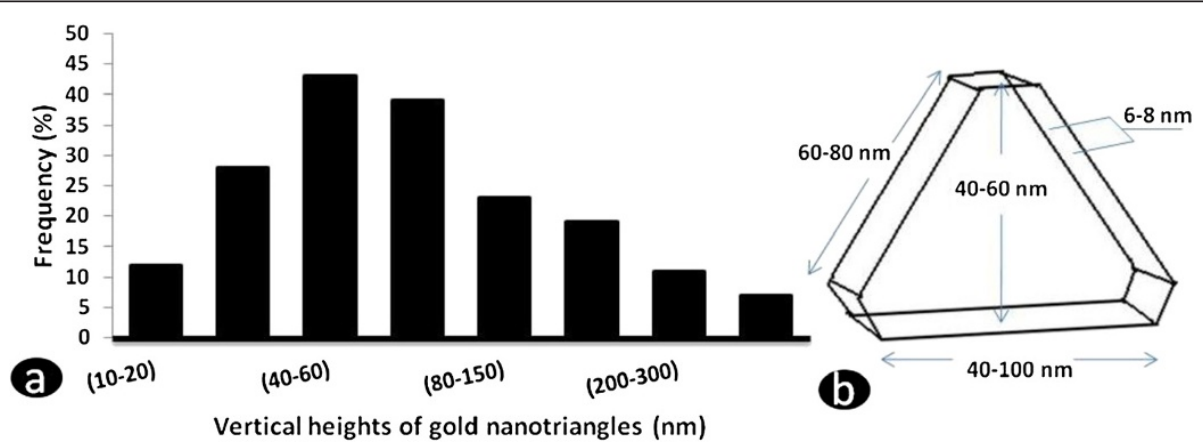

Figure 5 Vertical height and distribution measurement of gold nanotriangles. (a) The vertices measurement of average large nanotriangles was sketched (b) which shows that the vertical height is about 40 to $60 \mathrm{~nm}$, while edge margins range from 60 to $80 \mathrm{~nm}$. 


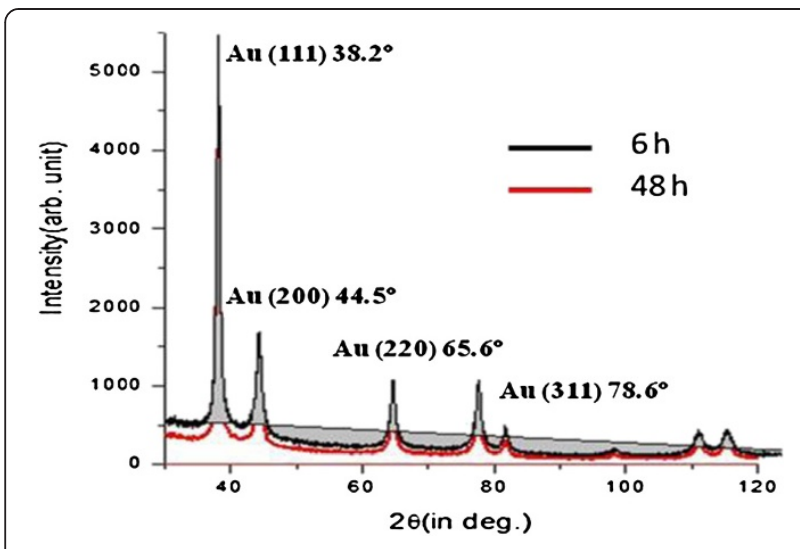

Figure 6 Typical XRD diffraction patterns for metal gold nanotriangles after 6 and $48 \mathrm{~h}$ incubation.

the spot can be indexed as face-centered cubic (fcc) structure of gold. The Bragg reflections obtained from the gold nanotriangles clearly correspond to the fcc crystalline structure of gold. The XRD pattern exhibits four peaks corresponding to the [111], [200], [220], and [311] diffraction peaks appearing at $2 \theta=38.2^{\circ}, 44.5^{\circ}, 65.6^{\circ}$, and $78.6^{\circ}$ of metal gold respectively (International Centre for Diffraction Data no. 4-0783), indicating that the precipitate is composed of pure crystalline gold (Figure 6). The AFM analysis of the gold nanotriangles was shown in Figure 7. The 3D image shows the surface roughness to a maximum of $700 \mathrm{~nm}$; however, many nanostructures have surface roughness bellow $100 \mathrm{~nm}$ size. Vertical stacking defaults of nanotriangles were observed as they grow in crystals, which results in overall vertical clumps of nanostructures (encircled area, inset in Figure 7). Figure 4a,b shows

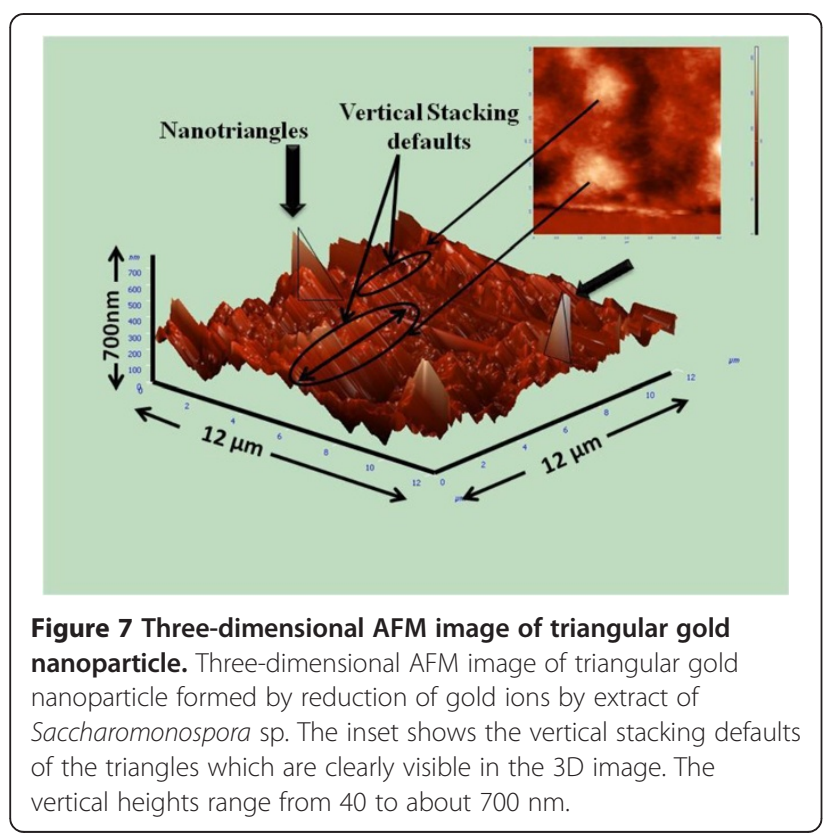

representative TEM micrograph of the thin sections of Saccharomonospora cells synthesized after challenging with chloroauric acid for $12 \mathrm{~h}$. At low magnification, the images showed small particles of gold (Figure 4a) representing several morphologies including triangles bound to the inner surface of the cell wall (Figure 4a,b); however, the triangular nanoparticles were varied in size (from smallest $26 \mathrm{~nm}$ to largest up to $100 \mathrm{~nm}$ ).

\section{Discussion}

The extract of endophytic actinomycetes Saccharomonospora sp. is for the first time investigated as potential reducing agent of noble metal aqueous ion solution, especially gold. This strain occupies a very unique niche 'the intercellular spaces' within internal healthy tissues of higher plants. This unique biotope often equipped these microbes with the phenomenal potential to cope with several environmental and anthropogenic stresses. By several means, these microbes have a greater living expectancy than their counterpart isolated from soil or any other conventional habitats. This is simply because these microbes have a rich suite of enzymes that work under stresses and probably are responsible for the better reduction of the noble metal ions as compared to their wild strains. When the biomass and fermentation extracts of Saccharomonospora sp. were brought into contact with $\mathrm{HAuCl}_{4}$ aqueous solution, a rapid change in the color of the reaction mixture was observed after $6 \mathrm{~h}$. This indicates the extracellular reduction of metal ions. The color of the nanoparticle aggregates appeared to vary as the interparticle distance changes, a phenomenon attributed to the SPR of nanoparticles [41]. Within $6 \mathrm{~h}$ of reaction incubation, the SPR peak observed further intensifies, which indicates a sharp reduction in the particle size; it probably seems that the nanoparticles were snipped at their margins with this length of incubation. This indicates that as the tips of the nanotriangles become snipped, the SPRs start a blue-shift (to shorter wavelengths) because the electron cloud density changes across the particle surface. Thus, the optical features to particle size shape and chemical environment is directly dependent on nanoparticles SPRs, charge distribution, and the dielectric environment. When excited, the SPRs of gold nanoparticles could scatter and/or absorb light in the visible or the near-infrared spectrum [42], an extremely useful and exploitable property for in vivo optical imaging techniques such as photoacoustic [43] and photon luminescence imaging [44]. The SDS protein profiling revealed that the bands corresponding to 42 and $50 \mathrm{kD}$ in lane 1 gradually declined in lane 2 and almost disappeared in lane 3. This indicates that polypeptides of this size range are involved in the synthesis and in stabilization of the gold nanoparticles. Aside from gold nanotriangles, there were large number of other shapes like hexagons and rough spheres also observed (Figure 4a). This clearly indicates 
that the longitudinal component of SPR band (as shown in Figure 1) arises due to the presence of gold nanotriangles in the reaction solution. It is remarkable that the edges of a few triangles were found truncated or snipped at their margins, which suggested that they were remarkably thin, and as measured by TEM, the thicknesses of these triangles were about 6 to $8 \mathrm{~nm}$. This was also in accordance with the UV-vis measurements which observed that as the reaction mixture was incubated for the longer time, a blue shift of the SPR bands was observed which is due to reduction of nanoparticles by snipping. Gold nanotriangles obtained by Saccharomonospora extract were found to be polycrystalline in nature. As seen from the XRD pattern, a very intense Bragg reflection for the [111] lattice was observed, suggesting that the [111]-oriented gold nanotriangles are lying vertical on the planar surface. This is also observed with AFM study (Figure 7), while the reflections correspond to [220] and [311] with lattice spacing of 1.44 and $1.23 \mathrm{~A}^{\circ}$ is specific for the triangular morphology. It is also notable that the ratio of intensity between the [200] and [111] diffraction peaks for the prepared sample is much lower than the standard, and this ratio rationally decreased as the particles size increased. This observation confirms that the as-formed gold nanoparticles are primarily dominated by [111] facets, which are quite consistent with the other diffraction observations [45]. The single crystal was not resolved with AFM study due to vertical stacking faults, and thus measurements and estimation of the size for single nanotriangles were not performed. To get some more insight into the phenomenon of microbial biofabrication, the treated biomass of Saccharomonospora sp. was subjected to the TEM analysis to know about the exact location of the reaction process within the cellular metabolism. At slightly higher magnification, one TEM image shows two nanotriangles overlapping each other on the cytoplasmic membrane (Figure 4b). Furthermore, the concentration of gold nanoparticles was much higher on the cytoplasmic membrane than on the cell wall. The presence of other shapes indicates that many particles were not transformed into triangle due to the lack of nucleation or undergone surface reorganization in such a way that they no longer exhibit the ideal triangular shape (Figure 4b). Although the mechanism of the formation of these special nanostructures in microbial systems is not fully explored, it seems that microbial systems might be easily manipulated for the controlled synthesis of nanoparticles, with a predefined shape such as nanotriangles. Thus, the possibility of achieving nanoparticle shape control synthesis in a microbial system is exciting.

\section{Conclusions}

The formation of gold nanoparticles of well-defined triangular shape and good monodispersity from endophytic
Saccharomonospora sp. was obtained with the specific SPR function. Additionally, two proteins (42 and $50 \mathrm{kD}$ ) identified were involved in the synthesis and stability of these highly structured nanotriangles. In the future, it would be significant to go deep into the mechanism of biosynthesis to technologically engineer the nanoparticles in order to achieve better control over the size, shape, and monodispersity of nanoparticles. The preliminary results obtained in this study indicate the possibility of getting control over the shape and size of nanoparticle in this microbial system.

\section{Competing interests}

Authors declare no competing financial interests. The authors have no other relevant affiliations or financial involvement with any organization or entity with a financial interest in or financial conflict with the subject matter of materials discussed in the manuscript apart from those disclosed. No writing assistance was utilized in the production of this manuscript.

\section{Authors' contributions}

VCV, SKS and SA hypothesized and executed the experiments, collected and interpreted the data, and wrote the manuscript. CU assisted in analyzing and interpretation of the results and writing manuscript. VCV and CU were involved in writing and editing of manuscript and interpretation of the results. All authors have read and approved the final manuscript.

\section{Authors' information}

VCV received his Ph.D. from Banaras Hindu University on natural product chemistry of plant associated microbes and currently serving as postdoctoral scientist at the Department of Microbiology, Banaras Hindu University, India. His research interest in nanobiotechnology is to bio-fabricate highly structured nanomaterials and their use in site-directed drug delivery. SA obtained her master's degree in biotechnology from Lovely Professional University, India and at present working as research fellow. Her major interest is to explore the possibilities of getting shape oriented synthesis of nanoparticle in microbial systems. CU is currently Professor at Humboldt University, Berlin, Germany. His research interest includes nanobiotechnology, apart from plant stress, eco-physiology, and chemical ecology. SKS is currently serving as a Research Officer at the Centre of Experimental Medicine and Surgery, Banaras Hindu University, India; apart from natural product chemistry study, he is also working on bacterial bio-films, bacterial resistance and nanobiotechnology.

\section{Acknowledgment}

The financial support from the University Grant Commission, New Delhi is gratefully acknowledged in the form of Dr. D.S. Kothari Postdoc fellowship to VCV (F. 4-2/2006 (BSR)/13-552/2011). Authors are thankful to the Professor-in -charge of the Centre of Experimental Medicine and Surgery (CEMS) for his support. Authors also extend their thanks to Prof. Dhananjai Pandey from the School of Material Science and Technology, Indian Institute of Technology, Banaras Hindu University for his assistance with the XRD and AFM studies and to Dr. Madhu Yashpal, scientist-in-charge, Electron Microscopy Facility, IMS-Banaras Hindu University, India for the TEM analysis of the gold nanoparticles.

\section{Author details}

${ }^{1}$ Centre of Experimental Medicine and Surgery, Institute of Medical Sciences, Banaras Hindu University, Varanasi 221005, India. ${ }^{2}$ Institute of Agriculture and Horticultural Science, Section Urban Horticulture, Humboldt-Universität zu, Lentzeallee Berlin 55-57, Berlin 14195, Germany. ${ }^{3}$ Department of Microbiology, Institute of Medical Sciences, Banaras Hindu University, Varanasi 221005, India.

Received: 10 January 2013 Accepted: 24 March 2013 Published: 8 April 2013 


\section{References}

1. Sun, Y, Xia, Y: Shape controlled synthesis of gold and silver nanoparticles. Science 298, 2176-2179 (2002)

2. Bond, GC, Thompson, DT: Status of catalysis by gold following an AURICAT workshop. Appl. Catal. A. 302, 1-4 (2006)

3. Corti, CW, Holliday, RJ, Thompson, DT: Progress towards the commercial application of gold catalysts. Top. Catal. 44, 331-343 (2007)

4. Li, J, Song, S, Li, D, Su, Y, Huang, Q, Zhao, Y, Fan, C: Multi-functional cross linked Au nano aggregates for the amplified optical DNA detection. Biosens. Bioelectron. 24, 3311-3315 (2009)

5. Zhou, X, Xu, W, Liu, G, Panda, D, Chen, P: Size-dependent catalytic activity and dynamics of gold nanoparticles at the single-molecule level. J. Am. Chem. Soc. 132, 138-146 (2010)

6. Karimi, B, Esfahani, FK: Gold nanoparticles supported on $\mathrm{Cs}_{2} \mathrm{CO}_{3}$ as recyclable catalyst system for selective aerobic oxidation of alcohols at room temperature. Chem. Comm. 37, 5555-5557 (2009)

7. Sardar, R, Funston, AM, Mulvaney, P, Murray, RW: Gold nanoparticles: past, present and future. Langmuir 25, 13840-13851 (2009)

8. Eaton, P, Doria, G, Pereira, E, Baptista, PV, Franco, R: Imaging gold nanoparticles for DNA sequence recognition in biomedical applications. IEEE Trans. Nanobiosci. 6, 282-288 (2007)

9. Zhou, D, Yang, L, Yang, R, Song, W, Peng, S, Wang, Y: Functionalized gold nanoparticles as additive to form polymer/metal composite matrix for improved DNA sequencing by capillary electrophoresis. Talanta 80, 195-201 (2009)

10. Qi, Y, Li, L, Li, B: Label-free detection of specific DNA sequence-telomere using unmodified gold nanoparticles as colorimetric probes. Spectrochim. Acta A Mol. Biomol. Spectrosc. 74, 127-131 (2009)

11. Huang, H, Huang, S, Liu, X, Zeng, Y, Yu, X, Liao, B, Chen, Y: Label-free optical biosensors based on $\mathrm{Au}^{2} \mathrm{~S}$-coated gold nanorods. Biosens. Bioelectron. 24, 3025-3029 (2009)

12. Escosura-Muñiz, A, Sánchez-Espinel, C, Díaz-Freitas, B, González-Fernández, A, Maltez-da Costa, M, Merkoçi, A: Rapid identification and quantification of tumor cells using an electrocatalytic method based on gold nanoparticles. Anal. Chem. 81, 10268-10274 (2009)

13. Lim, SY, Kim, JH, Lee, JS, Park, CB: Gold nanoparticle enlargement coupled with fluorescence quenching for highly sensitive detection of analytes. Langmuir 25, 13302-13305 (2009)

14. Lee, JS, Cho, J, Lee, C, Kim, I, Park, J, Kim, YM, Shin, H, Lee, J, Caruso, F: Layer-by-layer assembled charge-trap memory devices with adjustable electronic properties. Nat. Nanotechnol. 12, 790-795 (2007)

15. McMahon, JM, Henry, Al, Wustholz, KL, Natan, MJ, Freeman, RG, Van Duyne, RP, Schatz, GC: Gold nanoparticle dimer plasmonics: finite element method calculations of the electromagnetic enhancement to surface-enhanced Raman spectroscopy. Anal. Bioanal. Chem. 394, 1819-1825 (2009)

16. Wilcoxon, J: Optical absorption properties of dispersed gold and silver alloy nanoparticles. J. Phys. Chem. B 113, 2647-2656 (2009)

17. Liu, FK: Analysis and applications of nanoparticles in the separation sciences: a case of gold nanoparticles. J. Chromatogr. A 1216, 9034-9047 (2009)

18. Galanzha, El, Shashkov, EV, Kelly, T, Kim, JW, Yang, L, Zharov, VP: In vivo magnetic enrichment and multiplex photoacoustic detection of circulating tumour cells. Nat. Nanotechnol. 4, 855-860 (2009)

19. Yan, J, Pan, D, Zhu, C, Wang, L, Song, S, Fan, C: A gold nanoparticle-based microfluidic protein chip for tumor markers. J. Nanosci. Nanotechnol. 9, 1194-1197 (2009)

20. Kim, CS, Wilder-Smith, P, Ahn, YC, Liaw, LH, Chen, Z, Kwon, YJ: Enhanced detection of early-stage oral cancer in-vivo by optical coherence tomography using multimodal delivery of gold nanoparticles. J. Biomed. Opt. 14,034008 (2009)

21. Xie, JP, Lee, JY, Wang, DIC, Ting, YP: Identification of active biomolecules in the high-yield synthesis of single-crystalline gold nanoplates in algal solutions. Small 3, 672-682 (2007)

22. Xie, JP, Lee, JY, Wang, DIC: Synthesis of single-crystalline gold nanoplates in aqueous solutions through biomineralization by serum albumin protein. J. Phy. Chem. C. 111, 10226-10232 (2007)

23. Nangia, Y, Wangoo, N, Goyal, N, Shekhawat, G, Suri, CR: Facile biosynthesis of phosphate capped gold nanoparticles by a bacterial isolate Stenotrophomonas maltophilia. Appl. Phys. Lett. 94, 233901-233904 (2009)

24. Zhang, X, He, X, Wang, K, Wang, Y, Li, H, Tan, W: Biosynthesis of size-controlled gold nanoparticles using fungus, Penicillium sp. J. Nanosci. Nanotechnol. $10,5738-5744(2009)$
25. Fortin, D, Beveridge, TJ: Biologically induced mineralization by bacteria. In: Baeuerien, E (ed.) Biomineralization. From Biology to Biotechnology and Medical Applications, pp. 95-114. Wiley-VCH, Weinheim (2000)

26. Korbekandi, H, Iravani, S, Abbasi, S: Production of nanoparticles using organisms. Crit. Rev. Biotechnol. 29, 279-306 (2009)

27. Das, SK, Das, AR, Guha, AK: Gold nanoparticles: microbial synthesis and application in water hygiene management. Langmuir 25, 8192-8199 (2009)

28. Lee, JH, Roh, Y, Hur, HG: Microbial production and characterization of superparamagnetic magnetite nanoparticles by Shewanella sp. HN-41. J. Microbiol. Biotechnol. 18(9), 1572-1577 (2008)

29. Fu, J, Liu, Y, Gu, P, Tang, D, Lin, Z, Yao, B, Wen, S: Spectroscopic characterization on the biosorption and bioreduction of $\mathrm{Ag}(\mathrm{l})$ by Lactobacillus so.A09. Acta. Phys. Chim. Sin. 16, 779-782 (2000)

30. Mukherjee, P, Ahmad, A, Mandal, D, Senapati, S, Sainkar, S, Khan, MI, Ramani, R, Parischa, R, Ajayakumar, PV, Alam, M, Sastry, M, Kumar, R: Bioreduction of $\mathrm{AuCl}_{4}^{-}$ions by the fungus, Verticillium sp. and surface trapping of the gold nanoparticles formed. Angew. Chemie. Int. Eds. 40, 3585-3588 (2001)

31. Ahmad, A, Mukherjee, P, Seapati, S, Mandal, D, Khan, MI, Kumar, R, Sastry, M: Extracellular biosynthesis of silver nanoparticles using the fungus Fusarium oxysporum. Colloids Surf. B Biointerfaces 28, 313-318 (2003)

32. Sastry, M, Ahmad, A, Khan, Ml, Kumar, R: Biosynthesis of metal nanoparticles using fungi and actinomycete. Curr. Sci. 85, 162-170 (2003)

33. Ahmad, A, Senapati, S, Khan, Ml, Kumar, R, Sastry, M: Extracellular biosynthesis of monodisperse gold nanoparticles by a novel extremophilic actinomycete. Thermomonospora sp. Langmuir 19, 3550-3553 (2003)

34. Ahmad, A, Senapati, S, Khan, MI, Kumar, R, Ramani, R, Srinivas, V, Sastry, M: Intracellular synthesis of gold nanoparticles by a novel alkalotolerent actinomycete, Rhodococcus sp. Nanotech 14, 824-828 (2003)

35. Shankar, S, Ahmad, A, Pasricha, R, Sastry, M: Bioreduction of chloroaurate ions by geranium leaves and its endophytic fungus yields gold nanoparticles of different shapes. J. Mat. Chem. 13, 1822-1826 (2003)

36. Shankar, SS, Ahmed, A, Ankamwar, B, Sastry, M, Rai, A, Singh, A: Biological synthesis of triangular gold nanoprisms. Nat. Mat. 3, 482-488 (2004)

37. Robbens, J, Vanparys, C, Nobels, I, Blust, R, Van Hoecke, K, Janssen, C, De Schamphelaere, K, Roland, K, Blanchard, G, Silvestre, F, Gillardin, V, Kestemont, P, Anthonissen, R, Toussaint, O, Vankoningsloo, S, Saout, C, Alfaro-Moreno, E, Hoet, P, Gonzalez, L, Dubruel, P, Troisfontaines, P: Ecogeno- and human toxicology of bio-active nanoparticles for biomedical applications. Toxicol. 269, 170-181 (2010)

38. Verma, VC, Kharwar, RN, Gange, AC: Biosynthesis of antimicrobial silver nanoparticles by the endophytic fungus Aspergillus clavatus. Nanomed. 5, 33-40 (2010)

39. Verma, VC, Singh, SK, Solanki, R, Prakash, S: Biofabrication of anisotropic gold nanotriangles using extract of endophytic Aspergillus clavatus, as a dual functional reductant and stabilizer. Nanoscale Res. Lett. 6, 261 (2011)

40. Verma, VC, Gond, SK, Mishra, A, Kumar, A, Kharwar, RN, Gange, AC: Endophytic actinomycetes from Azadirachta indica A. Juss.: isolation, diversity, and anti-microbial activity. Microb. Ecol. 57, 749-756 (2009)

41. Elghanian, R, Storhoff, JJ, Mucic, RC, Letsinger, RL, Mirkin, CA: Selective colorimetric detection of polynucleotides based on the distance-dependent optical properties of gold nanoparticles. Science 277, 1078-1081 (1997)

42. Norman Jr, TJ, Grant, CD, Magana, D, Cao, D, Bridges, F, Liu, J, van Buuren, T, Zhang, JZ: Near infrared absorption of gold nanoparticle aggregates. J. Phys. Chem. B106, 7005-7012 (2002)

43. El-Brolossy, TA, Abdallah, T, Mohamed, MB, Abdallah, S, Easawi, K, Negm, S, Talaat, H: Shape and size dependence of the surface plasmon resonance of gold nanoparticles studied by photoacoustic technique. Eur. Phys. J. 153, 361-364 (2008)

44. Durr, NJ, Larson, T, Smith, DK, Korgel, BA, Sokolov, K, Ben-Yakar, A: Twophoton luminescence imaging of cancer cells using molecularly targeted gold nanorods. Nano Lett. 7, 941-945 (2007)

45. Sun, X, Dong, S, Wang, E: Large-scale synthesis of micrometer-scale single-crystalline Au plates of nanometer thickness by a wet-chemical route. Angew. Chem. Int. Eds. 46, 6360-6362 (2004)

\section{doi:10.1186/2228-5326-3-21}

Cite this article as: Verma et al:: Biogenic gold nanotriangles from Saccharomonospora sp., an endophytic actinomycetes of Azadirachta indica A. Juss. International Nano Letters 2013 3:21. 